Ambient Science, 2018: Vol. 05(2); 01-05 DOI:10.21276/ambi.2018.05.2.ta01

\title{
ambient
}

SCIENCE

Vol. 05(2): 01-05

Year 2018

TECHNOSCIENCE ARTICLE

\section{An Efficient Treatment System for Arsenic Removal from Groundwater}

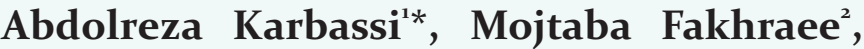 Sanaz Tajziehchi', Toktam Shahriari', Saeed Maddah ${ }^{1}$}

'School of Environment, College of Engineering, University of Tehran, Tehran, Iran

${ }^{2}$ Water Resources Science Graduate Program, University of Minnesota Twin Cities, MN, United States

Study Area: Bijar, Iran

Coordinates: $35^{\circ} 5^{\prime} 22^{\prime \prime} \mathrm{N} ; 47^{\circ} 36^{\prime} 10^{\prime \prime} \mathrm{E}$

Keywords: ; Reverse Osmosis; Domestic Water Treatment System, Contamination Health

\begin{abstract}
Abbreviations used in this work:
As-Arsenic, ADD-Average Daily Dose, BW -Body Weight, C-Concentration, DW-Daily Water intake, EC-Electrical Conductivity, MCL-Maximum Concentration Level, $\mu \mathrm{g} / \mathrm{L}$ -Microgram per Liter, mg/L-Milligram per Liter, RO-Reverse Osmosis, TDS-Total Dissolved Solids, TS-Total Solids, Ur-Risk Unit, USEPA-United States Environmental Protection Agency, WHO-World Health Organization
\end{abstract}

\section{Introduction:}

Arsenic has a long history in many branches of science. Degradation along with the erosion of bedrocks has led to the exposure of arsenic-bearing rocks. Particularly the ground waters that are in continuous touch with such rocks may show elevated amounts of arsenic. In some countries, anthropogenic sources along with bedrocks are the main sources of groundwater contamination with various forms of arsenic (Islam et al., 2018; Sobhanardakani, 2018; Nordstrom, 2002). It has been shown that occurrence of Arsenic in ground waters of the western part of USA is mainly due to its release from iron oxide that has raised arsenic concentrations exceeding $10 \mu \mathrm{g} / \mathrm{L}$ in groundwater (Welch et al., 200o). Higher Arsenic concentrations were reported where $\mathrm{FeOOH}$ reduction takes place; such areas are marked with grey sediments (McArthur et al., 2004). Many researchers have preferred to minimize the adverse effects of arsenic through information and awareness campaign (Hadi, 2003; Madajwics et al., 2007).

Under the aerobic and anaerobic conditions, the arsenic might be presented in the form of arsenate and arsenite respectively. In many cases as well as in the present study, the arsenite form of arsenic is felt more important for its toxicity (Jain \& Ali, 2000; Matschullat, 200o; Desesso et

\section{Abstract}

Consumption of water contaminated with arsenic causes acute and chronic health effects. The purpose of the present work is to develop a simple and economical procedure for removal of arsenic from potable waters. We analyzed the arsenic concentration in several sources drinking water from Bijar county, Iran. An optimized arsenic removal unit was proposed. and an inductively coupled plasma was used for measurements. For optimization of such removal unit, effects of different parameters including adsorbent dose, $\mathrm{pH}$, contact time, initial concentration and interfering ions on the removal of arsenic from groundwater were standardized. Results revealed that the average arsenic concentration in the studied area was more than the national standard limit, ranging from 11.17 to $2167.98 \mu \mathrm{g} / \mathrm{L}$. Based on our results, the reverse osmosis (RO) could be suggested as the best and optimum method with $98 \%$ efficiency. The results of the health risk assessment of arsenic for residents during the study period showed that the groundwater resources were severely contaminated with arsenic and could cause carcinogenesis problems for the population in the studied area.

al., 1998). To mitigate adverse health effect resulted from arsenic contamination, the World Health Organization (Gomez-Caminero et al., 2001) and United States Environmental Protection Agency (Schulman, 2000) determined a new maximum allowable level (MCL) of $10 \mu \mathrm{g}$ / L in drinking water, considerably lower than the previous limit, indicating the need of arsenic removal from drinking water. According to the USEPA guidelines, the best available technology for arsenic removal is defined as the method with high removal efficiency, easy installation and operation, and low installation and maintenance cost (Pirnie, 200o). As a result, many studies had attempted to bring out various side effects of arsenic. Such studies include pregnancy, skin cancer, metabolism, developing organisms and so on (Ahmad et al., 20o1; Geber et al., 1982; Concha et al., 1998). Many efforts were taken to remove arsenic from potable waters. Such efforts included using a porous pellet adsorbent with an eff iciency of over $47 \%$ (Te et al., 2017; 2018). In some studies, various sorption materials and introducing iron hydroxide granulates were used as the best sorbent (Daus et al., 2004). Some studies have shown that advanced oxidation processes should be used in the absence of sulfite for obtained higher arsenic removal (Zaw \& Emett, 2002; Bissen \& Frimmel, 2003;

*Corresponding Author: akarbasi@ut.ac.ir 
Comninellis et al., 2008). Some researchers had preferred various magnetite graphene oxide for arsenic removal with an eff iciency over 99\% (Chandra et al., 2010; Luo et al., 2012; Yoon et al., 2016).

Following the serious arsenic contamination in the studied area (Mosaferi et al., 2003), the present research aims for producing an easy and eff icient system that would be cost-effective, as well as improving quality of the drinking water in terms of arsenic contamination and health risk assessment and in accordance with USEPA and WHO standards.

\section{Methodology:}

Bijar is a city located in the eastern part of the Kurdistan province at an altitude of 1940 meters above sea level. It is the largest city in Kurdistan province with an area of 7730 $\mathrm{km} 2$. The city is in a cold and semi-arid region enjoying annual rainfall, relative humidity and an average temperature of about $338 \mathrm{~mm}, 47 \%$ and $11{ }^{\circ} \mathrm{C}$ respectively.

In this study, to account for different input loads, the treatment system with six removal stages was designed. Removal stages are presented as follows:

$\checkmark$-Polypropylene layer

- Granular Activated Carbon layer

$\checkmark$ - Block Carbon layer

$\checkmark$-sand layer

$\checkmark$-Membrane Filter

$\checkmark$-Mineral layer

Table-1: Standard Methods (1998) used to measure physiochemical parameters

\begin{tabular}{lll}
\hline Parameter & Unit & Instrument used \\
\hline $\mathrm{pH}$ & - & Wide range $\mathrm{pH}$ meter \\
$\mathrm{DO}$ & $\mathrm{mg} / \mathrm{L}$ & DO meter \\
$\mathrm{EC}$ & $\mathrm{ds} / \mathrm{m}$ & Conductivity meter \\
$\mathrm{TDS}$ & $\mathrm{mg} / \mathrm{L}$ & Calculation \\
Temperature & ${ }^{\circ} \mathrm{C} \mathrm{S}$ & Thermometer \\
\hline
\end{tabular}

The spiral membranes were constructed from one or more membrane envelopes around a perforated central tube. The permeate passed through the membrane into the envelope and spirals inward to the central tube for collection. Other factors that influence performance were the pressure of the water inlet, water temperature, concentration of the solutes, and density of the particulate matter, TDS in the water. The membranes used for RO had dense layers in the polymer matrix where the chemical separation occurred. The design of the membrane was based on permitting water (cut-off limit around 200 Daltons) to flow through this dense layer. To analyze the water samples before and after unit treatment, one liter of water samples without acid protection were held in the refrigerator at a temperature of $4{ }^{\circ} \mathrm{C}$ and transferred to the lab to analyze physiochemical parameters such as $\mathrm{pH}$, electrical conductivity (EC), total dissolved solids (TDS) and total solids (TS). Methods used to measure different parameters are presented in Table-1. Analyses of As, Sb, and $\mathrm{Mn}$ in water samples were conducted by inductively coupled plasma (ICP-70oo VER2, Shimadzu).

\section{Resultsand Discussion:}

The results of physicochemical parameters of water samples from Hassan Khan, Ghojagh and Narenjak villages are presented in Table-2. As shown in Table 2, there is not much difference between the physicochemical parameters of water samples from the sampled villages. Table-2. physiochemical parameters of water samples from (1) Hassan Khan, (2) Ghojagh and (3) Narenjak villages located in the vicinity of Bijar country (mean of 36 potable water samples).

Table-2: The results of Arsenic concentration in samples from 1- Hassan Khan, 2- Ghojagh and 3- Narenjak

\begin{tabular}{|c|c|c|c|c|c|c|c|c|}
\hline \multicolumn{3}{|c|}{ Mean } & \multicolumn{3}{|c|}{ Minimum } & \multicolumn{3}{|c|}{ Maximum } \\
\hline 1 & 2 & 3 & 1 & 2 & 3 & 1 & 2 & 3 \\
\hline \multicolumn{4}{|c|}{ Parameter: pH } & \multicolumn{5}{|l|}{-} \\
\hline 7.8 & $7 \cdot 9$ & 7.8 & $7 \cdot 7$ & $7 \cdot 7$ & $7 \cdot 7$ & $7 \cdot 9$ & 8.0 & 8.0 \\
\hline \multicolumn{9}{|c|}{ Parameter: dissolved Oxygen (DO), mg/L } \\
\hline 2.5 & 2.2 & 2.9 & 2.2 & 2.1 & 2.7 & 2.8 & 3.1 & $3 \cdot 3$ \\
\hline \multicolumn{9}{|c|}{ Electrical Conductivity (EC), ds/cm } \\
\hline 550 & 445 & 396 & 250 & 200 & 220 & 780 & 740 & 660 \\
\hline \multicolumn{9}{|c|}{ Total Dissolved Solid (TDS), mg/L } \\
\hline 320 & 305 & 290 & 250 & 220 & 210 & 550 & 530 & 520 \\
\hline \multicolumn{9}{|c|}{ Temperature, ${ }^{\circ} \mathrm{C}$} \\
\hline 20 & 21 & 21 & 17 & 17 & 17 & 22 & 23 & 22 \\
\hline
\end{tabular}

The results of Arsenic concentration in samples from the studied area is given in Table-2. As shown in Table-3, the highest concentrations of arsenic were found in Hassan Khan village $(2200 \mu \mathrm{g} / \mathrm{L})$. The concentrations of arsenic in potable waters of Ghojagh Village and Narenjak village were about 200 and $35 \mu \mathrm{g} / \mathrm{L}$, respectively.

Table-3: Concentration of Arsenic in potable waters three studied villages (mean of 36 potable water samples, $\mu \mathrm{g} / \mathrm{L}$ )

\begin{tabular}{llll}
\hline Location & Mean & Minimum & Maximum \\
\hline Hassan Khan village & 2200 & 1120 & 2230 \\
Ghojagh village & 200 & 146 & 270 \\
Narenjak & 35 & 31 & 39 \\
\hline
\end{tabular}

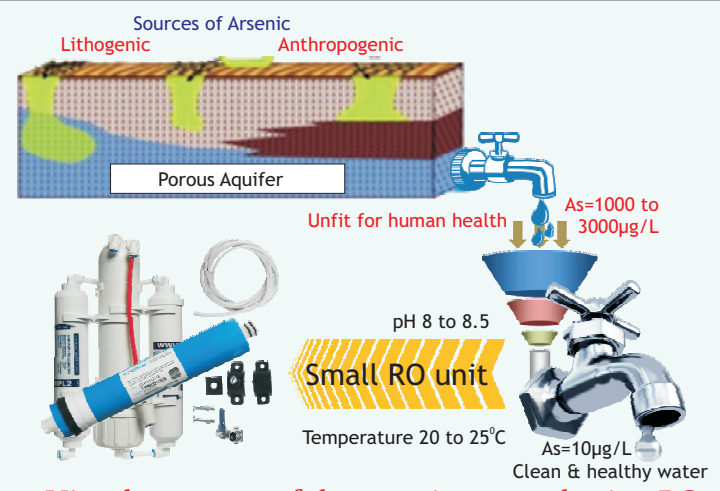

Figure-1: Visual summary of the arsenic removal using RO treatment system 


\section{TECHNOSCIENCE ARTICLE}

Based on the values presented in Table-3, arsenic removal with $\mathrm{RO}$ was tested in three different concentrations; 1000, 2000 and $3000 \mu \mathrm{g} / \mathrm{L}$. About 4 liters of each contaminated water samples were passed three times through the six stage filters. The water samples passed through the filters were again subjected to ICP analysis. The results of the analysis revealed that arsenic removal's efficiency varies between 89 to $99 \%$. As a matter of fact higher initial concentrations $(3000 \mu \mathrm{g} / \mathrm{L})$ showed more removal efficiency than the other initial concentration (1000 to $2000 \mu \mathrm{g} / \mathrm{L}$ ). In the experiment, a very good efficiency rate for arsenic removal was obtained without any pre-oxidation step. Subsequently, it was tried to find out optimum $\mathrm{pH}$ for removal of arsenic. For this purpose salts and hydrochloric acid were used to stabilize $\mathrm{pH}$ at 6.0, 7.5, 8.o and 8.5. All other parameters were kept constant.

Table-4: Effect of various $\mathrm{pH}$ ranges on the performance of arsenic treatment by filters $\left(\mathrm{T}=\mathbf{2 0 ^ { \circ }}, \mathrm{P}=\mathbf{2 0 0 p s i}\right)$

\begin{tabular}{lcc}
\hline $\mathrm{pH}$ ranges & $\begin{array}{l}\text { Concentration after } \\
\text { treatment }\end{array}$ \\
\hline \multicolumn{3}{l}{ Initial As concentration-2000 $\mu \mathrm{g} / \mathrm{L}$} \\
6.0 & 97 & 95.15 \\
7.0 & 52 & 97.40 \\
7.5 & 40 & 98.00 \\
8.0 & 25 & 98.75 \\
8.5 & 24 & 98.80 \\
\hline
\end{tabular}

Table-5: Effect of various $\mathrm{pH}$ ranges on the performance of arsenic treatment by filters $(\mathrm{pH}=8, \mathrm{P}=200 \mathrm{psi})$

\begin{tabular}{lll}
\hline $\begin{array}{l}\text { Temperature } \\
\text { degree Celcius }\end{array}$ & $\begin{array}{l}\text { Concentration after } \\
\text { treatment }\end{array}$ & \% of as Removal \\
\hline \multicolumn{2}{l}{ Initial As concentration-20oo $\mu \mathrm{g} / \mathrm{L}$} \\
20 & 25 & 98.75 \\
25 & 200 & 90.0 \\
30 & 350 & 82.5 \\
35 & 420 & 79.0 \\
45 & 490 & 75.5 \\
\hline
\end{tabular}

Along with $\mathrm{pH}$, temperature also played an important role in removing the arsenic from groundwater. To determine the optimal temperature for arsenic removal, samples with a concentration of $2000 \mu \mathrm{g} / \mathrm{L}$ was set up and consolidated at the temperature of 20, 25, 30, 35, 40 degrees Celsius. Other parameters were kept unchanged. Each mode was used in $\mathrm{pH}$ of urban water (ca. 8) and pressure in the range of 200 psi. With increasing temperature, the amount of flux through the membrane increases, which in turn, would decrease the efficiency of arsenic removal. So that the maximum removal eff iciency varies in the range of $75 \%-90 \%$ (Table- 5 ). In other words, the arsenic removal efficiency decreases as the water temperature increases. Shipley et al. (2009) showed that $\mathrm{pH}$ and temperature do not affect the adsorption of arsenic on magnetite nanoparticles. However, elevated temperatures (for instance geothermal springs) may increase the ability of laterites for adsorption of arsenic (Partey et al., 2008).
Ambient Science, 2018: Vol. 05(2); 01-05 DOI:10.21276/ambi.2018.05.2.ta01

A $30^{\circ} \mathrm{C}$ is an optimum temperature for removal of arsenic when granular activated carbon is used (Mondal et al., 2007). The proposed method (six stages, including Polypropylene layer, Granular Activated Carbon layer, Block Carbon layer, sand layer, Membrane Filter, Mineral layer) for removing arsenic in water is more practical for small communities. Methods like activated aluminum and reverse osmosis play an important role in arsenic removal, but these are practical only for pre-purges of water supplies and they are not suitable for small communities. In general, the system can treat 25 liters per day which is good enough to serve a family of 8 members.

Table-6: Carcinogenic and non-carcinogenic risk calculation of Arsenic in groundwater resources in three studied villages

Village C ADDd Ur-cancer Risk Ur-non Risk $\mathrm{mg} / \mathrm{L} \mathrm{mg} / \mathrm{kg} \mathrm{kg}$-day/mg cancer cancer Non$\mathrm{kg}$-day/mg cancer

\begin{tabular}{lllllll}
\hline 1 & 2.2 & 0.0929 & 1.5 & 0.13935 & 0.003 & 0.0002787 \\
2 & 0.20 & 0.0087 & 1.5 & 0.01305 & 0.003 & 0.0000261 \\
3 & 0.035 & 0.0015 & 1.5 & 0.00225 & 0.003 & 0.0000045 \\
\hline \multicolumn{7}{l}{ 1-Hassan Khan, 2-Ghojagh, 3-Narenjak }
\end{tabular}

1-Hassan Khan, 2-Ghojagh, 3-Narenjak

Subsequently, human health risk assessment was carried out by the following formulae:

$\mathrm{ADDd}=\mathrm{DW}^{*} \mathrm{C} / \mathrm{BW}$

Where ADDd is the amount of dose that enters to the body through drinking water, DW is the average daily volume for drinking water (in this study about 3 liters), $C$ is the concentration of arsenic in water $(\mathrm{mg} / \mathrm{L})$, and $\mathrm{BW}$ is the body weight, which is considered as 70 kilograms.

To conduct the dose-reaction assessment for residents, Environmental Protection Agency suggested a linear model by which quantify the relationship between risk and its effects:

Risk $=$ ADDd * $\mathrm{Ur}$

Where Ur is risk unit that is designated as a factor of the relative risk and depends on the concentration or available dose and accepts truevalues.

Based on the formulae 1 and 2, the health risk assessment was computed for the studied area (Table 6). We also took Narenjak Village into our human health risk assessment calculation, as its arsenic concentration was less than EPA standard $(=0.05 \mathrm{mg} / \mathrm{L})$ but higher than WHO standard $(=0.01 \mathrm{mg} / \mathrm{L})$. Taken all the data and risk calculation together, the amount of dose entered to the body and the human health risk associated with arseniccontaminated drinking water were calculated. Unfortunately, groundwater resources in the studied area may possess a risk of carcinogenic disease (Table-6). Till date, such higher concentrations of arsenic is not reported from other parts of the world. These reports have mainly focused on the geology of the area and its role on higher contents of arsenic (Li et al., 2012; Aloupi et al., 2009). The allowable level for arsenic daily average intake in drinking water should be less than $10 \mu \mathrm{g}$ for the daily average 
consumption of 2 liters of water. In areas without natural sources of arsenic, allowable level in drinking water is less than $5 \mu \mathrm{g} / \mathrm{L}$, and $40 \mu \mathrm{g}$ in food, and this limit is even lower $(<10 \mu \mathrm{g})$ for an inorganic form of arsenic (Pirnie, 1999). To further minimize the risk associated with the drinking of water contaminated with carcinogenic elements like arsenic, allowable limit of arsenic is $0.01 \mathrm{mg} / \mathrm{L}$ based on the latest WHO guidelines for drinking water quality (GomezCaminero et al., 2001). Guidelines state that limit of $10 \mu \mathrm{g} / \mathrm{L}$ is temporary due to the lack of suitable testing methods and this value could still be further decreased based on health condition. Based on EPA guideline, MCL for Arsenic is 50 $\mu \mathrm{g} / \mathrm{L}$ before the year 2000, and is expected to get a stricter limit (less than $2 \mu \mathrm{g} / \mathrm{L}$ to $20 \mu \mathrm{g} / \mathrm{L}$ ) in the revised version. EPA declared that the limit of $10 \mu \mathrm{g} / \mathrm{L}$ for arsenic in drinking water is based on extensive studies on skin cancer that is caused by arsenic, as well as the feasibility of treatment systems to comply with the specif ied MCL. In the year 1998, the Europe Commission (EC) also determined the limit of $10 \mu \mathrm{g} / \mathrm{L}$ as MCL for arsenic. It should be noted that the risk of skin cancer associated with exposure to these concentrations during the lifetime is $6 \times 10^{-4}$.

\section{Conclusion:}

In the present work, the eff iciency of the reverse osmosis system in removing the arsenic pollutant from drinking water was investigated. Arsenic was very efficiently removed by reverse osmosis. Our results showed that the removal rates in the RO system fall between 95 to $98 \%$ when only a membrane filter was used. For reaching higher arsenic removal rate, two or three membrane filters could be also implemented. As shown earlier, when the two filters were installed on the device, the removal rate was found to be $98 \%$ at a concentration of $3000 \mu \mathrm{g} / \mathrm{L}$. The removal of arsenic was strongly affected by the solution $\mathrm{pH}$. When dealing with groundwater with high values of arsenic, ambient $\mathrm{pH}$ (about 8) adjustment is also recommended. However, new drinking water standard for arsenic would be difficult to meet in small rural communities which rely upon groundwater as their source of supply. This treatment system for such areas would also be costly, and also require technical help which most of these communities cannot effort. This study shows that RO systems may provide an affordable alternative to conventional water treatment, and yet significant management and regulatory issues must be drastically addressed.

\section{Acknowledgements:}

This paper is based on work supported by the Iran National Science Foundation (Grant No. 92041715). Any opinions, findings, and conclusions or recommendations expressed in this article are those of the authors and do not necessarily reflect those of the Iran National Science Foundation.

\section{References:}

Ahmad, S.A., Sayed, M.H., Barua, S., Khan, M.H., Faruquee, M.H., Jalil, A., Hadi, S.A. \& Talukder H.K., (2001): Arsenic in drinking water and pregnancy outcomes. Environ. Health Perspect., 109(6):629-631.

Aloupi, M., Angelidis, M.O., Gavriil, A.M., Koulousaris, M., Varnavas, S.P., (2009): Influence of geology on arsenic concentrations in ground and surface water in central Lesvos, Greece. Environ. Monit. Assess., 151(1-4):383-396.

Bissen, M. \& Frimmel, F.H., (2003): Arsenic - a Review. Part II: Oxidation of Arsenic and its Removal in Water Treatment. Acta Hydrochim. Hydrobiol., 31(2):97-107.

Chandra, V., Park, J., Chun, Y., Lee, J.W., Hwang, I. \& Kim, K.S., (2010): Water-dispersible magnetite-reduced graphene oxide composites for arsenic removal. ACSNano, 4(7):3979-3986.

Comninellis, C., Kapalka, A., Malato, S., Parsons, S. A., Poulios, I. \& Mantzavinos, D. (2008): Advanced oxidation processes for water treatment: advances and trends for R\&D. J. Chem. Technol. Biotechnol., 83(6):769-776.

Concha, G., Vogler, G., Lezcano, D., Nermell, B. \& Vahter, M., (1998): Exposure to inorganic arsenic metabolites during early human development. Toxicol Sci., 44(2):185-190.

Daus, B., Wennrich, R. \& Weiss, H., (2004): Sorption materials for arsenic removal from water: a comparative study. Water Res., 38(12):2948-2954.

DeSesso, J., Jacobson, C., Scialli, A., Farr, C. \& Holson, J., (1998): An assessment of the developmental toxicity of inorganic arsenic. Reprod. Toxicol., 12(4):385-433.

Gerber, G.B., Maes, J. \& Eykens, B. (1982): Transfer of antimony and arsenic to the developing organism. Arch. Toxicol., 49(2):159168.

Gomez-Caminero, A., Howe, P.D., Hughes, M., Kenyon, E., Lewis, D.R., Moore, M., Aitio, A., Becking, G.C. \& Ng, J. (2001): Arsenic and Arsenic compounds, Environment Health Criteria (2nd Ed.), Pub. by: World Health Organization (WHO), Geneva.

Hadi, A. (2003): Fighting arsenic at the grassroots: experience of BRAC's community awareness initiative in Bangladesh. Health Policy Plan., 18(1):93-100.

Islam, K., Zahra, F. T., Chowdhury, M. \& Biswas, S.M., (2018): Analysis of the Stringency of Drinking Water Quality Standards of Bangladesh in Comparison to the USA, EU, Japanese, and Indian Standards. Pollution, 4(2):263-272.

Jain, C.K. \& Ali, I. (200o): Arsenic: occurrence, toxicity and speciation techniques. Water Res., 34(17):4304-4312.

Li, S., Xiao, T. \& Zheng, B. (2012): Medical geology of arsenic, selenium and thallium in China. Sci. Total Environ., 421422:31-40.Luo, X., Wang, C.,

Luo, S., Dong, R., Tu, X. \& Zeng, G., (2012): Adsorption of As (III) and $\mathrm{As}(\mathrm{V})$ from water using magnetite $\mathrm{Fe}_{3} \mathrm{O}_{4}$-reduced graphite oxide- $\mathrm{MnO}_{2}$ nanocomposites. Chem. Eng. J., 187:4552.

Madajewicz, M., Pfaff, A., Van Geen, A., Graziano, J., Hussein, I., Momotaj, H., Sylvi, R. \& Ahsan, H., (2007): Can information alone change behavior? Response to arsenic contamination of groundwater in Bangladesh.J. Dev. Econ., 84(2):731-754.

Matschullat, J., (2000): Arsenic in the geosphere - a review. $\underline{\text { Sci. }}$ Total Environ., 249(1-3): 297-312.

McArthur, J. M., Banerjee, D. M., Hudson-Edwards, K. A., Mishra, 


\section{TECHNOSCIENCE ARTICLE}

R., Purohit, R., Ravenscroft, P., Cronin, A., Howarth, R.J., Chatterjee, A., Talukder, T., Lowry, D., Houghtona, S. \& Chadhah, D.K. (2004): Natural organic matter in sedimentary basins and its relation to arsenic in anoxic ground water: the example of West Bengal and its worldwide implications. Appl. Geochem., 19(8):1255-1293.

Mohan, D., Pittman Jr, C.U., Bricka, M., Smith, F., Yancey, B., Mohammad, J., Steele, P.H., Alexandre-Franco, M.F., GómezSerrano, V. \& Gong, H. (2007): Sorption of arsenic, cadmium, and lead by chars produced from fast pyrolysis of wood and bark during bio-oil production. I. Colloid Interf. Sci., 310(1):5773.

Mondal, P., Balomajumder, C. \& Mohanty, B. (2007): A laboratory study for the treatment of arsenic, iron, and manganese bearing ground water using $\mathrm{Fe}^{3+}$ impregnated activated carbon: effects of shaking time, $\mathrm{pH}$ and temperature. L. Hazard. Mater., 144(1-2):420-426.

Mosaferi, M., Yunesion, M., Mesdaghinia, A., Naidu, A., Nasseri, S. \& Mahvi, A. H. (2003): Arsenic occurrence in drinking water of IR of Iran: the case of Kurdistan Province. In Fate of arsenic in the environment. Dhaka: BUET-UNU International Symposium, International Training Network Centre, Bangladesh University of Engineering and Technology, United Nations University, Tokyo; pp. 1-6.

Nordstrom, D.K. (2002): Worldwide occurrences of arsenic in ground water. $\underline{\text { science, } 21(296): 2143-2145 .}$

Partey, F., Norman, D., Ndur, S. \& Nartey, R., (2008): Arsenic sorption onto laterite iron concretions: temperature effect. $L$. Colloid Interf. Sci., 321(2):493-500.

Pirnie, M. (1999): Technologies and costs for removal of arsenic from drinking water. Pub. by: International Consultant Inc., Ohio, \& Malcolm Pirnie Inc., Arizona. 289p.
Ambient Science, 2018: Vol. 05(2); 01-05 DOI:10.21276/ambi.2018.05.2.ta01

Schulman, A.E., (2000): Arsenic occurrence in public drinking water supplies. United States Environmental Protection Agency. Available from: Off ice of Groundwater and Drinking Water, EPA 815-R-oo-023.

Shipley, H.J., Yean, S., Kan, A.T. \& Tomson, M.B., (2009): Adsorption of arsenic to magnetite nanoparticles: effect of particle concentration, $\mathrm{pH}$, ionic strength, and temperature. Environ. Toxicol. Chem., 28(3):509-515.

Sobhanardakani, S. (2018): Arsenic Health Risk Assessment through Groundwater Drinking (Case Study: Qaleeh Shahin Agricultural Region, Kermanshah Province, Iran). Pollution, 4(1):77-82.

Te, B., Wichitsathian, B., Yossapol,C. \& Wonglertarak, W., (2018): Coexisting arsenate and arsenite adsorption from water using porous pellet adsorbent: Optimization by response surface methodology. Global J. Environ. Sci. Manag., 4(2):141152.

Te, B., Wichitsathian, B., Yossapol, C. \& Wonglertarak, W. (2017): Development of low-cost iron mixed porous pellet adsorbent by mixture design approach and its application for arsenate and arsenite adsorption from water. Adsorp. Sci. Tech., 36(12):372-392.

Welch, A.H., Westjohn, D.B., Helsel, D.R., Wanty, R.B., (200o): Arsenic in ground water of the United States: occurrence and geochemistry. Groundwater, 38(4):589-604.

Yoon, Y., Park, W.K., Hwang, T.M., Yoon, D.H., Yang, W.S. \& Kang, J.W., (2016): Comparative evaluation of magnetite-graphene oxide and magnetite-reduced graphene oxide composite for As (III) and As (V) removal.JHazard. Mater., 304:196-204.

Zaw, M. \& Emett, M.T., (2002): Arsenic removal from water using advanced oxidation processes. Toxicol. Lett., 133(1):113-118. 